\title{
Access and Quality of Postnatal Care in Low- and Middle - Income Countries: A Pragmatic Review
}

\author{
Preeti Priyadarshani ${ }^{1,2}$, Anderson Borovac-Pinheiro ${ }^{2,3}$ and Thomas F Burke ${ }^{2,4,5 *}$ \\ ${ }^{1}$ Department of Obstetrics and Gynecology, All India Institute of Medical Sciences, India \\ ${ }^{2}$ Department of Emergency Medicine, Massachusetts General Hospital, Massachusetts, USA \\ ${ }^{3}$ Department of Obstetrics and Gynecology, University of Campinas, Campinas (SP), Brazil \\ ${ }^{4}$ Harvard TH Chan School of Public Health, Boston, Massachusetts, USA
}

Submission: August 26, 2020; Published: September 15, 2020

*Corresponding author: Preeti Priyadarshani, Department of Obstetrics and Gynecology, All India Institute of Medical Sciences, Gorakhpur (UP), India

Abstract

The postnatal period is comprised of the 42 days after delivery and is a vulnerable time for mothers and newborns. Postnatal care has traditionally been the lowest priority in the continuum of maternal healthcare. In this paper, we review the literature on postnatal care in low- and middle - income countries to identify gaps in care, their causes, and means to address identified deficiencies. Adequate postnatal care may not be available to women, or women may decide to not use care available to them. Quality of care may also be sub-par when compared with existing standard guidelines. Health systems across low- and middle - income countries need to be strengthened to ensure availability of quality postnatal care. Maternal and neonatal morbidity and mortality data should be used to drive policy changes.

Keywords: Postnatal care; LMIC; Public health

\section{Introduction}

The postnatal period is comprised of the 42 days after delivery $[1,2]$. It is a vulnerable time for mothers and newborns. More mothers and newborns in low- income and middle-income countries (LMICs) lose their lives during the postnatal period than at any other time, yet this period consistently has the lowest coverage on the continuum of maternal care [2-4]. The Covid-19 pandemic has affected the health of mothers and newborns both directly and indirectly, the consequences of which will only be clear with the passage of time. However, emerging data suggests a significant rise in maternal mortality in low-income and mediumincome countries. [5]. Worldwide, most maternal, and newborn deaths occur in LMICs, the majority of which are preventable. [6]. Eighty percent of maternal deaths and up to two-thirds of newborn deaths could be avoided by effective health interventions during and after birth $[7,8]$. Maternal deaths, however, represent only a minority of women that suffer untoward consequences from giving birth. Approximately 20 times the number of lives lost suffer serious health consequences [9]. Many countries have taken steps to provide skilled delivery services and antenatal care. However, these measures have shown limited success in reducing maternal and newborn mortality. About 140 million women give birth every year worldwide [10]. Although a primary aim of the Sustainable Development Goals (SDGs) is for universal health coverage by 2030, providing quality postnatal care to all these women is a challenge for both developing and developed countries [11]. Availability and utilisation of postnatal care is far more inadequate in LMICs due to poverty, lack of transportation, insufficient health care access, and overall weak health systems [11]. Until recently, many countries did not collect data on postnatal care services and coverage. Less than one in three women delivering in LMICs receive any postnatal care, yet up to $40 \%$ of women in low-income countries develop complications following delivery $[3,12]$. Nearly $15 \%$ of mothers in low-income countries encounter life-threatening conditions in the postpartum period [12]. The objective of this paper was to conduct a pragmatic review on the access to, and quality of postnatal care in LMICs. We sought to identify gaps and make recommendations for strengthening health systems.

\section{Materials and Methods}

We conducted a search using Pubmed, Google Scholar, and the Cochrane database. Search terms included combinations of 


\section{Global Journal of Reproductive Medicine}

postpartum care, postnatal care, and LMIC. We tried multiple combinations and modified search results to identify relevant papers. The search strategy included MeSH terms. We included studies that met the following criteria: a) all studies that described postnatal care in low and middle- income countries, both for home and institutional deliveries b) all literature published in the English language c) all studies published between 1st January 1999 to 31 January 2019 (search was later modified to include articles published between 1 February 2019 to 31 March 2021). We manually screened abstracts of identified papers for relevance. We also conducted a hand search of references from identified research articles to find further published literature. All relevant studies were included irrespective of study design. Literature on individual low-or middle-income countries was not specifically sought, but all identified publications relevant to lowand middle- income countries were included. We applied WHO recommendations on postnatal care of mothers and newborns, and WHO recommendations on intrapartum care for a positive childbirth experience as benchmarks for evaluating quality of care $[1,10]$.

\section{Result}

\section{Access to postnatal care}

Healthcare coverage during the postnatal period varies widely around the world. South Asian countries fare better than Sub-Saharan Africa countries in providing care within the critical 24-hour window after birth [13]. The proportion of women that receive postnatal care within 24 hours ranges from $5 \%$ in Ethiopia to $33 \%$ in Malawi, $40 \%$ in Nepal, $58 \%$ in Pakistan and $63 \%$ in Senegal $[13,14]$. When considering care provided within the 48 hour window after birth, many countries fare better; from $9.7 \%$ in Ethiopia, 31\% in Tanzania, 45\% in Nepal to $70 \%$ in Cambodia [14-17]. Coverage of postnatal care increases when considering access within the first 42 days after birth. However, many women do not receive their initial postnatal care for more than a month after delivery $[18,19]$. Additionally, most women in LMICs able to access postnatal care services receive less than the recommended four postnatal visits [20]. Extensive nationwide lockdowns and disruption of routine health services during the pandemic further decrease the availability of routine postnatal services [21]. The negative public perception of hospitals as hotspots for contracting Covid - 19 also leads to avoidance of hospital visits [22,23]. Quality care within the first two days of life can decrease neonatal mortality by up to two-thirds [7]. However, not all countries measure coverage of care for neonates as an independent metric [23]. Newborns are vulnerable to delays in care - a few minutes, hours or days can lead to loss of life from sepsis, low birth weight and other complications [2].

\section{Barriers to access of postpartum care}

Many women do not utilize available postnatal care services. One study reported that while postnatal care was available to $65 \%$ of women, actual coverage was only $31.3 \%$ [19]. Barriers to availability and utilisation of postnatal care are described by three delays: delays in decision to seek care, delays in contact with a health worker or facility, and delays in adequate health service provision.Cultural, social and normative barriers are a major deterrent to seeking timely care $[24,25]$. Home deliveries are still prevalent in many parts of the world [26]. Women that deliver at home are at high risk of not receiving timely postnatal care [2,2731]. They may even be discouraged from seeking postnatal care due to negative attitudes of healthcare providers towards them [32]. Only 9\% of Ugandan women delivering at home receive early postnatal care within 48 hours [33]. Many cultures have the custom of confinement of the mother and newborn for a period after delivery. $[1,18,20]$ Women often do not seek medical help if they do not perceive the need for medical care [25,34]. They may also not perceive problems serious enough to spend precious time and resources to visit a health facility $[1,35]$. This can in part be due to low awareness of the danger signs and symptoms of health problems [36]. Women sometimes choose to seek services of traditional birth attendants or other complimentary healers as they feel that care is more personalised, respectful, and culturally appropriate. They may even be deterred from accessing health facilities due to concerns about quality of care and emotional abuse [18,37]. Perceived high cost of health services and insufficient knowledge about government-run programs can also be a barrier [25,34]. The socio-economic conditions of women in low- and middle- income countries have been disproportionately affected by the ongoing Covid 19 pandemic [38] Lockdowns and travel restrictions imposed to control the pandemic, and the fear of contracting Covid-19 while visiting a health facility, can lead to a decrease in the number of women utilizing routine antenatal and postnatal facilities $[21,39]$. Women who receive antenatal care or delivery services from skilled providers are more likely to use postnatal care services. $[36,40]$. Geographic accessibility of health care centres plays an important role in determining use of care [25]. Inadequate counselling by health workers after delivery can lead to loss of follow-up $[25,28,34]$. Lack of availability of neonatal vaccines at health facilities may demotivate mothers from making a trip to a health facility [34]. The gender of healthcare providers may additionally play a role, with women in some cultures only seeking access to healthcare services if the providers are female $[37,41]$. Lack of access to an affordable transport system and long distances from health facilities are barriers to connecting with the health system after a decision to seek care has been made. $[2,34,35]$ The COVID- 19 associated lockdowns and the consequent suspension of public transport facilities impose restrictions on travel to health facilities. The effect of access to antenatal care on postnatal care attendance is uncertain, but it has been shown that women that engage with the health system during pregnancy and at delivery are more likely to access postnatal care [42]. Where available, women may delay notifying service providers for home visits, which can further lead to delays in care [43]. There is a shortage of Emergency Obstetric Care (EmOC) services throughout LMICs. $[24,44]$. Care is often only provided to either the mother or the baby, and care for the other is missed even 


\section{Global Journal of Reproductive Medicine}

after reaching the health facility [18]. Health providers may not be aware of existing postnatal care policies [29]. Many health centres at various levels in LMICs are inadequately staffed to handle deliveries and postpartum care $[9,35,44,45]$. The shortage of skilled human resources is more pronounced in rural and remote areas [9]. Inadequate attendance of healthcare providers, both in home visits and in health care facilities, means inadequate coverage of women that need care [34]. Less than two-thirds of women delivering at a health facility in Uganda received postnatal care in the first two days of birth [33]. In many LMICs there are considerable missed opportunities to provide care to mothers and their babies simultaneously [13,19].

\section{Quality of postnatal care}

While the steep increase in the number of women that deliver in facilities across LMICs has been a tremendous accomplishment over the past decade, women who deliver in health facilities often receive poor postnatal care [2]. Women frequently do not receive adequate postnatal care prior to leaving the facility and often are discharged within few hours of birth $[13,18,19]$. In one study, almost $40 \%$ of maternity staff did not know essential management of postpartum haemorrhage and more than $50 \%$ had inadequate knowledge of newborn care [19]. Women discharged from a facility within a few hours of delivery are unlikely to return for future emergent or routine postpartum care $[18,30,43,46]$. Only a small proportion of women are adequately assessed and cared for at follow-up visits [19]. Care providers may sometimes focus on immunisation of the baby but miss the opportunity to provide care to the mother during the same visit $[19,25]$. A study in Uganda reported that while $87 \%$ babies attending postnatal clinics were examined, only $15 \%$ mothers reported their blood pressure was measured, $25 \%$ had an abdominal examination and $22 \%$ were asked about abnormal bleeding [19]. Another study from Haiti reported a higher number of women who were examined $194 \%$ had blood pressure taken, 78\% had abdomen examined, $94 \%$ were asked about wellbeing) showing difference in assessment in different parts of the world. [47]. WHO recommends home visits in the first week after birth for care of mother and baby [1]. Although home-based postnatal care can lead to better neonatal health and maternal satisfaction, it is not commonly available and is inadequate even where it exists $[2,43,46,48,49]$. Counselling on family planning and the signs and symptoms of complications that may require seekig care is recommended for all women after giving birth [1] Only a minority of women in LMICs are offered counselling as a part of postnatal care, resulting in considerable knowledge gaps among postpartum women regarding postnatal care of mothers and babies $[47,50,51]$. Poor quality of counselling services may also be responsible for low uptake of postpartum contraception [50,52]. Exclusive breastfeeding is practiced by a minority of women in LMICs and reflects poor advocacy, education, and support $[2,23,26]$. Data are sparse on the amount and extent of counselling provided to women regarding high-risk danger signs after delivery. One study reported that more than three out of four women had low awareness of postnatal danger signs for mother and baby, even though more than $50 \%$ of mothers were provided information on danger signs after delivery. [20] Variable coverage of postnatal vitamin supplementation is reported from different studies $[19,20]$ Postnatal mental health problems are under-identified and under-treated in LMICs, even as WHO recommends providing psychological support to all women at risk of postpartum depression [1,3]. Policy and programmatic environment. Most countries focus on postnatal care as a part of the spectrum of MCH care. Countries like Uganda, Thailand, Niger, and Brazil eliminated user fees to improve attendance of postnatal visits [53-56]. India, Nepal, Indonesia, and Mexico initiated conditional cash transfer schemes while Rwanda and Burkina Faso introduced performance-based financing based on quality as well as quantity of services provided at the health facilities [34,57-61]. While these programs may have increased service utilisation in most areas, their effect on decreasing maternal and neonatal morbidity and mortality remains uncertain $[53,54,62]$. A Cochrane review published in 2017 found that while cash transfer programs may increase people's use of services, they may not lead to improvement of health indicators. The effects of change in user fees on service utilisation were also deemed uncertain [63].

\section{Discussion}

Evidence based guidelines for postnatal care of mothers and babies are frequently updated by WHO [1]. Published literature suggests that implementation of these guidelines varies widely across LMICs. Broad deficiencies in postnatal care exist at macroand micro- system levels across many countries, often leading to sub-par care of mothers and babies [4] The pandemic and the response to the pandemic are further negatively affecting these deficiencies. Access to health services has been closely correlated with utilization of health services [35]. Empowering women with higher community- level autonomy and education is likely to increase the use of existing health services $[12,13,24,35,42]$. Health programs that ensure greater participation of male partners and family members in women's healthcare need to be promoted $[2,20]$. The first contact of pregnant woman with a health system should be used to formulate a care and support plan, with an emphasis on the significance of the continuum of care, even after delivery for both mother and child. Efforts must be taken during and after the pandemic to reduce the time lost in transportation to health services, as well as the time spent in hospital waiting rooms. Separate and secure treatment pathways must be designed for the care of obstetric patients wherever feasible during this time [22]. The use of various media tools such as mass media and text messages for care of women in socially and geographically vulnerable populations to develop prompt health seeking behaviour offer new opportunities [13]. Since a significant number of women residing in LMICs still deliver at home, the role of community involvement in reducing maternal and neonatal morbidity and mortality should be explored further in the context of different countries and communities [2,12,27]. 


\section{Global Journal of Reproductive Medicine}

Merely increasing access to postnatal care is alone insufficient to improve maternal and neonatal health outcomes. Access to care must be accompanied with quality service from a skilled provider who additionally has ready access to higher levels of care $[2,24]$. EmOC services need to be strengthened and integrated into health systems [24]. Facilities that provide postnatal care must be equipped with the necessary equipment, drugs and supporting infrastructure $[37,44]$. Health care providers need to be regularly updated with recent guidelines to provide quality care $[4,24]$. Management protocols for emergency and routine healthcare visits should be in place. Postnatal counselling services need to be strengthened across LMICs and should include an emphasis on respectful quality care [37]. A discharge checklist/ visit checklist can be locally developed to ensure coverage of all aspects of maternal and neonatal care, and to help in early diagnosis of problems $[1,46]$. Dedicated postpartum clinics and postpartum registers can be established where resources permit $[19,64]$. Provision of comprehensive maternal and neonatal care simultaneously under one roof is more likely to increase attendance and improve outcomes [49]. Synchronised scheduling of visits of mothers and newborns will ensure that care is received by both, even if care is provided by different providers to mother and baby [49]. Steps need to be taken to ensure timely recruitment and retention of health workers, including timely payment of adequate wages and incentives $[24,63]$. The ratio of healthcare providers to the population served needs to be maintained [45]. Separate nursing staff should be dedicated to postnatal wards wherever feasible. [45] When the number of health care providers are inadequate, group discussions and counselling sessions for postpartum women may be utilized [45]. Regulations may be put in place to ensure attendance of employed health workers, especially during night shifts and weekends $[24,37,45]$. Special provision of health workers for home visits need to be ensured wherever required, especially in rural and remote areas $[7,30]$. Steps may be put in place to decrease the administrative workload of clinical health workers across cadres [65]. An integrated care plan including provision of both facility-based and homebased care needs to be developed and implemented. The role of home visits in decreasing maternal and neonatal morbidity and mortality should be explored further in the context of local settings $[30,46]$. National guidelines on postnatal care may not exist in many countries. In such scenarios, research is required on the means to promote large-scale uptake of WHO guidelines. Research is also needed to guide modifications of guidelines to best suit local needs $[24,46]$. Strengthening health systems at all levels from the ground-up is essential to provide optimal care to women delivering in LMICs. A strong political will to invest in a country's healthcare is essential to improving access to quality care being of women before, during and after delivery [2,24]. Data are powerful tools to inform quality of care. Maternal and neonatal morbidity and mortality data from audits should be used to drive policy changes at national and international levels. [2] Feedback from women that have recently delivered can be used to improve care provided at the local level. [50].

\section{Conclusion}

As many high-income countries are shifting their focus from preventing morbidity and mortality to promoting maternal and newborn wellness, most LMICs are struggling to achieve the 2030 SDG targets for maternal and newborn mortality [10]. Since government-supported health care programs continue to be the mainstay of care in many countries, governments and supporting agencies should work toward strengthening public health systems and establishing integrated healthcare services by providing a continuum of maternal and neonatal care that best serves their populations. During this time of pandemic, additional efforts are needed to ensure equitable access to quality postnatal care. This review has several limitations. Only literature published or available in the English language was included, therefore it is possible that relevant publications in other languages were missed. While the methodology of systemic reviews was employed, we did not record excluded articles. However, multiple authors selected relevant articles to minimise sampling bias.

\section{Authors' Contributions}

PP, AB-P and TB conceived of the study. PP, AB-P collected the data. $\mathrm{PP}, \mathrm{AB}-\mathrm{P}$ and $\mathrm{TB}$ wrote the first version of the manuscript. All the authors contributed with edits and draft revisions and the authors have no conflict of interest.

\section{Acknowledgement}

We thank the Massachusetts General Hospital Department of Emergency Medicine for support in developing this review.

\section{References}

1. (2013) World Health Organization. WHO recommendations on Postnatal care of the mother and newborn.

2. Warren C, Daly P, Toure L, Mongi P (2017) Postnatal care (In:)Lawn J Kerber K. Opportunities for Africa's newborns: Practical data, policy and programmatic support for newborn care in Africa. Postnatal care. The Partnership for Maternal, Newborn and Child Health.

3. Hulton L, Murray S, Thomas D. The Evidence Towards MDG 5: A Working Paper.

4. Pallangyo E, Mbekenga C, Olsson P, Eriksson L, Bergström A (2018) Implementation of a facilitation intervention to improve postpartum care in a low-resource suburb of Dar es Salaam, Tanzania. Implementation Science 13: 102.

5. Chmielewska B, Barratt I, Townsend R, Khilafat E, van der Meulen J, et al. (2021) Effects of the COVID-19 pandemic on maternal and perinatal outcomes: a systematic review and meta-analysis. The Lancet Global Health 9(6): e759-e772.

6. (2015) WHO, UNICEF, UNFPA, World Bank Group, United Nations Population Division. Trends in maternal mortality: 1990 to 2015. Estimates by WHO, UNICEF, UNFPA, World Bank Group and the United Nations Population Division, Geneva: World Health Organization.

7. Baqui AH, Ahmed S, El Arifeen S, Darmstadt GL, Rosecrans AM, et al. (2009) Effect of timing of first postnatal care home visit on neonatal mortality in Bangladesh: a observational cohort study. BMJ 339: b2826 


\section{Global Journal of Reproductive Medicine}

8. Landers C (2009) Maternal and Newborn Health: A Global Challenge, U.S. Fund for UNICEF Youth Report - The State of the World's Children. New York, USA.

9. (2010) World Health Organization. Countdown to 2015 Decade re-port taking stock of maternal, newborn and child survival.

10. (2011) World Health Organization. WHO recommendations: intrapartum care for a positive childbirth experience.

11. (2019) World Health Organization. SDG 3: Ensure healthy lives and promote wellbeing for all at all ages.

12. Langlois ÉV, Miszkurka M, Zunzunegui MV, Ghaffar A, Ziegler D, et al. (2015) Inequities in postnatal care in low-and middle-income countries: a systematic review and meta-analysis. Bull World Health Organ 93(4): 259-270.

13. Ministry of Health and Population (MOHP), New ERA, and ICF International (2012) Nepal Demographic and Health Survey 2011 Kathmandu, Nepal: Ministry of Health and Population, New ERA, and ICF International, Calverton, Maryland.

14. Singh K, Story WT, Moran AC (2016) Assessing the Continuum of Care Pathway for Maternal Health in South Asia and Sub-Saharan Africa. Matern Child Health J 20(2): 281-289.

15. EDHS (2012) Ethiopia demographic and health survey, 2011. Central Statistical Agency Addis Ababa, Ethiopia ICF International Calverton, Maryland, USA.

16. (2010) Tanzania Demographic and Health Survey National Bureau of Statistics Dar es Salaam, Tanzania, ICF Macro, Calverton, Maryland, USA.

17. (2019) World Health Organization. Success factors for women's and children's health: Cambodia

18. Mrisho M, Obrist B, Schellenberg JA (2009) The use of antenatal and postnatal care: perspectives and experiences of women and health care providers in rural southern Tanzania. BMC Pregnancy Childbirth 9: 10.

19. Wilunda C, Oyerinde K, Putoto G, Lochoro P, Giovanni DO, et al. (2015) Utilisation and quality of maternal and neonatal health care services in Karamoja region, Uganda: a health facility-based survey. Reprod Health 12: 30 .

20. Mon AS, Phyu MK, Thinkhamrop W, Thinkhamrop B (2018) Utilization of full postnatal care services among rural Myanmar women and its determinants: a cross-sectional study. F1000Res 7: 1167.

21. Roberton T, Carter ED, Chou VB (2020) Early estimates of the indirect effects of the COVID-19 pandemic on maternal and child mortality in low-income and middle-income countries: a modelling study. Lancet Glob Health 8: e901-908.

22. Kumari V, Mehta K, Choudhary R (2020) COVID-19 outbreak and decreased hospitalisation of pregnant women in labour. Lancet Glob Health 8(9): e1116-e1117.

23. (2020) The National Road Map Strategic Plan to Improve Reproductive, Maternal, Newborn, Child \& Adolescent Health in Tanzania.

24. Lassi ZS, Musavi NB, Maliqi B (2016) Systematic review on human resources for health interventions to improve maternal health outcomes: evidence from low- and middle-income countries. Hum Resour Health 14: 10

25. Nabukera SK, Witte K, Muchunguzi C, Bajunirwe F, Batwala VK, et al. (2006) Use of postpartum health services in rural Uganda: knowledge, attitudes, and barriers. J Community Health 31(2): 84-93.

26. Kerber KJ, de Graft Johnson JE, Bhutta ZA, Okong P, Starrs A, et al. (2007) Continuum of care for maternal, newborn, and child health: from slogan to service delivery. Lancet 370: 1358-1369.
27. Engmann CM, Hodgson A, Aborigo R, Adongo PL, Moyer CA (2016) Addressing the continuum of maternal and newborn care in Ghana: implications for policy and practice. Health Policy Plan 31(10): 13551363.

28. Baldo MH, Al-Mazrou YY, Aziz KM, Farag MK, Al-Shehri SN (1995) Coverage and quality of natal andpostnatal care: women's perception, Saudi Arabia. J Trop Pediatr 41(S1): 30-37.

29. Sibanda JQ Saungweme I, Nleya C, Mutyambizi MP, Rutgers RA (2001) Postnatal care in Bubi district deserves more attention. Cent Afr J Med 47:103-108

30. (2009) World Health Organization, UNICEF: WHO/UNICEF Joint Statement: Home visits for the newborn child: a strategy to improve survival. Switzerland.

31. Tessema ZT, Yazachew L, Tesema GA, Teshale AB (2020) Determinants of postnatal care utilization in sub-Saharan Africa: a meta and multilevel analysis of data from 36 sub-Saharan countries. Ital J Pediatr 46(1): 175.

32. Sacks E, Masvawure TB, Atuyambe LM, Neema S, Macwan'gi M, et al. (2017) Postnatal Care Experiences and Barriers to Care Utilization for Home- and Facility-Delivered Newborns in Uganda and Zambia. Matern Child Health J 21: 599.

33. Ndugga P, Namiyonga NK, Sebuwufu D (2020) Determinants of early postnatal care attendance: analysis of the 2016 Uganda demographic and health survey. BMC Pregnancy Childbirth 20(1): 163.

34. Titaley C, Hunter C, Heywood P, Dibley M (2010) Why don't some women attend antenatal and postnatal care services? a qualitative study of community members' perspectives in Garut, Sukabumi and Ciamis districts of West Java Province, Indonesia. BMC Pregnancy and Childbirth 10: 61.

35. Dhakal S, Chapman GN, Simkhada P P, Teijlingen ER,Stephens J and Raja AE (2007) Utilisation of postnatal care among rural women in Nepal. BMC Pregnancy and Childbirth 7: 19.

36. Chaka EE, Abdurahman AA, Nedjat S, Majdzadeh R (2019) Utilization and Determinants of Postnatal Care Services in Ethiopia: A Systematic Review and Meta-Analysis. Ethiop J Health Sci 29(1): 935-944.

37. Srivastava A, Avan BI, Rajbangshi P, Bhattacharyya S (2015) Determinants of women's satisfaction with maternal health care: a review of literature from developing countries. BMC Pregnancy Childbirth 15: 97.

38. Burki T (2020) The indirect impact of COVID-19 on women. Lancet Infect Dis 20: 904-910.

39. Khalil A, von Dadelszen P, Khilafat E (2020) Change in obstetric attendance and activities during the COVID-19 pandemic. Lancet Infect Dis 21(5):e115.

40. Geremew AB, Boke MM, Yismaw AE (2020) The Effect of Antenatal Care Service Utilization on Postnatal Care Service Utilization: A Systematic Review and Meta-analysis Study. J Pregnancy 73: 63-242.

41. Bhan N, McDougal L, Singh A, Atmavilas Y, Raj A (2020) Access to women physicians and uptake of reproductive, maternal and child health services in India. E Clinical Medicine 20: 100-309.

42. Tarekegn SM, Lieberman LS, Giedraitis V (2014) Determinants of maternal health service utilisation in Ethiopia: analysis of the 2011 Ethiopian Demographic and Health Survey. BMC Pregnancy Childbirth 14: 161.

43. Greco G, Daviaud E, Owen H, Ligowe R, Chimbalanga E, et al. (2017) Malawi three district evaluation: Community-based maternal and newborn care economic analysis. Health Policy Plan 32: i64-i74. 


\section{Global Journal of Reproductive Medicine}

44. Lama TP, Munos MK, Katz J, Khatry S, LeClerq S, Mullany L (2020) Assessment of facility and health worker readiness to provide quality antenatal, intrapartum, and postpartum care in rural Southern Nepal. BMC Health Serv Res 20: 16.

45. Bradley S, Kamwendo F, Chipeta E, Chimwaza W, de Pinho H, McAuliffe E (2015) Too few staff, too many patients: a qualitative study of the impact on obstetric care providers and on quality of care in Malawi. BMC pregnancy and childbirth 15(1).

46. Yonemoto N, Dowswell T, Nagai S, Mori R (2017) Schedules for home visits in the early postpartum period. The Cochrane database of systematic reviews 7: CD009326.

47. Mirkovic KR, Lathrop E, Hulland EN (2017) Quality and uptake of antenatal and postnatal care in Haiti [published correction appears in BMC Pregnancy Childbirth. BMC Pregnancy Childbirth 17(1): 52

48. Tiruneh G T, Shiferaw C B and Worku A (2019) Effectiveness and costeffectiveness of home-based postpartum care on neonatal mortality and exclusive breastfeeding practice in low-and-middle-income countries: a systematic review and meta-analysis. BMC Pregnancy Childbirth 19: 507.

49. Firoz T, McCaw-Binns A, Filippi V (2018) A framework for healthcare interventions to address maternal morbidity. Int J Gynaecol Obstet 141.

50. Speizer I S, Fotso J C, Okigbo C, Mbacke C, and Seck C (2013) Influence of integrated services on postpartum family planning use: A crosssectional survey from urban Senegal. BMC Public Health 13: 752-761.

51. Beraki GG, Tesfamariam EH, Gebremichael A, Yohannes V, Haile K Tewelde S (2020) Knowledge on postnatal care among postpartum mothers during discharge in maternity hospitals in Asmara: a crosssectional study. BMC Pregnancy Childbirth 20,17.

52. Dev R, Kohler P, Feder M, Unger JA, Woods NF, (2019) A systematic review and meta-analysis of postpartum contraceptive use among women in low- and middle-income countries. Reprod Health 16(1): 154.

53. Amouzou AO, Habi K, Bensaid (2012) Reduction in child mortality in Niger: a Countdown to 2015 country case study. Lancet 380: 11691178.

54. Mbonye AK, Sentongo M, Mukasa GK, Byaruhanga R, Sentumbwe Mugisa 0, et al (2012) Newborn survival in Uganda: a decade of change and future implications. Health Policy Plan 27(3).
55. Sousa A, Hill K, Dal Poz MR (2010) Sub-national assessment of inequality trends in neonatal and child mortality in Brazil. Int J Equity Health 9: 21.

56. Vapattanawong $\mathrm{P}$, Hogan MC, Hanvoravongchai P, Gakidou E, Vos T, et al. (2007) Reductions in child mortality levels and inequalities in Thailand: analysis of two censuses. Lancet 369: 850-855.

57. Lim SS, Dandona L, Hoisington JA, James SL, Hogan MC (2017) India's Janani Suraksha Yojana, a conditional cash transfer programme to increase births in health facilities: an impact evaluation. The Lancet 375: 2009-2023.

58. Cortez R, Seemeen S, Chowdhury S, Sarker I (2014) Maternal and child survival: findings from five countries experience in addressing maternal and child health challenges.

59. Bhutta ZA and Aleem S (2013) A Review of External Assistance and Aid Effectiveness for Maternal and Child Health: Challenges and Opportunities. WIDER Working.

60. Shapira G, Kalisa I, Condo J, Humuza J, Mugeni C, et al. (2018) Going beyond incentivizing formal health providers: Evidence from the Rwanda Community Performance-Based Financing program. Health Econ 27(12): 2087-2106.

61. Steenland M, Robyn P, Compaore P, Kabore M, TapsobaB, et al. (2017) Performance-based financing to increase utilization of maternal health services: Evidence from Burkina Faso. SSM-Population Health 179-184.

62. Powell-Jackson T, Mazumdar S, Mills A (2015) Financial incentives in health: New evidence from India's Janani Suraksha Yojana. J Health Econ 43: 154-169.

63. Wiysonge CS, Paulsen E, Lewin S (2017) Financial arrangements for health systems in low-income countries: an overview of systematic reviews. Cochrane Database Syst Rev 9(9): CD011084.

64. Nowik CM, Pudwell J, Smith GN (2018) Evaluating the postpartum maternal health clinic: How patient characteristics predict follow-up. J ObstetGynaecol Can 38: 930-935.

65. Serour GI (2009) Healthcare workers and the brain drain. Int J Gynaecol Obstet 106(2): 175-178.

\section{Your next submission with Juniper Publishers will reach you the below assets}

- Quality Editorial service

- Swift Peer Review

- Reprints availability

- E-prints Service

- Manuscript Podcast for convenient understanding

- Global attainment for your research

- Manuscript accessibility in different formats

( Pdf, E-pub, Full Text, Audio)

- Unceasing customer service

Track the below URL for one-step submission

https://juniperpublishers.com/online-submission.php 